PROCEEDINGS B

rspb.royalsocietypublishing.org

\section{Research}

Cite this article: Eliason CM, Hudson L, Watts T, Garza H, Clarke JA. 2017 Exceptional preservation and the fossil record of tetrapod integument. Proc. R. Soc. B 284: 20170556.

http://dx.doi.org/10.1098/rspb.2017.0556

Received: 15 March 2017

Accepted: 25 July 2017

\section{Subject Category:}

Palaeobiology

\section{Subject Areas:}

evolution, palaeontology

\section{Keywords:}

Lagerstätten, soft tissue preservation, taphonomy, terrestrial, feathers, hair

\section{Authors for correspondence: \\ Chad M. Eliason \\ e-mail: celiason@fieldmuseum.org \\ Julia A. Clarke \\ e-mail: julia_clarke@jsg.utexas.edu}

Electronic supplementary material is available online at https://dx.doi.org/10.6084/m9.

figshare.c.3849775.

\title{
Exceptional preservation and the fossil record of tetrapod integument
}

Chad M. Eliason ${ }^{1,2,3}$, Leah Hudson ${ }^{1}$, Taylor Watts ${ }^{1}$, Hector Garza ${ }^{1}$ and Julia A. Clarke ${ }^{1,2}$

\footnotetext{
${ }^{1}$ Department of Geological Sciences, and ${ }^{2}$ Department of Integrative Biology, The University of Texas at Austin, Austin, TX 78713, USA
}

${ }^{3}$ Field Museum of Natural History, Chicago, IL 60605, USA

(iD) CME, 0000-0002-8426-0373

The fossil record of exceptionally preserved soft tissues in KonservatLagerstätten provides rare yet significant insight into past behaviours and ecologies. Such deposits are known to occur in bursts rather than evenly through time, but reasons for this pattern and implications for the origins of novel structures remain unclear. Previous assessments of these records focused on marine environments preserving chemically heterogeneous tissues from across animals. Here, we investigate the preservation of skin and keratinous integumentary structures in land-dwelling vertebrates (tetrapods) through time, and in distinct terrestrial and marine depositional environments. We also evaluate previously proposed biotic and abiotic controls on the distribution of 143 tetrapod Konservat-Lagerstätten from the Permian to the Pleistocene in a multivariate framework. Gap analyses taking into account sampling intensity and distribution indicate that feathers probably evolved close to their first appearance in the fossil record. By contrast, hair and archosaur filaments are weakly sampled (five times less common than feathers), and their origins may significantly pre-date earliest known occurrences in the fossil record. This work suggests that among-integument variation in preservation can bias the reconstructed first origins of integumentary novelties and has implications for predicting where, and in what depositional environments, to expect further discoveries of exquisitely preserved tetrapod integument.

\section{Introduction}

The fossil record consists primarily of hard, mineralized tissues (bones, mollusc shells), with relatively few instances of soft tissue preservation [1]. Exceptional preservation of soft tissue in Konservat-Lagerstätten [2] provides rare, yet significant, palaeontological data. For example, exquisitely preserved soft tissues have revealed the relationships between living and extinct groups (reviewed in [3]), and informed the origins of integumentary innovations [4,5] and major transitions in evolution (e.g. gain of powered flight) [6]. Bias in the fossil record of soft tissue affects inferences about the tempo and mode of evolution, and understanding what factors drive the distribution of Lagerstätten through time is therefore critical in accounting for uncertainty in evolutionary analyses. However, relatively few studies have described patterns of distribution of Lagerstätten through time [7-9] or proposed taphonomic mechanisms that might explain these patterns $[7,8]$.

It has been over 20 years since the distribution of land-dwelling vertebrate Konservat-Lagerstätten through time has been treated [7], and since then there have been major new discoveries (e.g. the Jehol Group) that have contributed important data on soft tissue preservation and tetrapod integument. In 1993, 44 Konservat-Lagerstätten (32 marine and 12 terrestrial) were surveyed by depositional environment and age across the Phanerozoic [7]. These authors found statistically significant heterogeneity in temporal distribution and considered sedimentary outcrop area and sea level as potential explanatory variables [7]. More recently, specifically marine Konservat-Lagerstätten were addressed [9] ( $n=44$ Phanerozoic marine localities) and their relationship with variability in 
$\mathrm{CO}_{2}$ levels was explored [8] ( $n=83$ Phanerozoic localities). These more recent studies surveyed soft tissue preservation limited to marine environments as a single class of depositional environment but varying by major animal group (e.g. including both protostomes and deuterostomes) [8] and soft tissue type (e.g. organs, muscles, integument). Such analyses of several tissue types and taxa preserved in a single depositional setting can reveal how major climatic events might explain patterns of Lagerstätten occurrence through time. By contrast, investigating one specific kind of tissue across several depositional environments may uniquely shed light on factors affecting tissue preservation in depositional environments with distinct chemistries [10].

The integument of land-dwelling vertebrates, or tetrapods-including epidermis and dermis and associated alpha and beta keratin integumentary structures (e.g. scales, hair and feathers)-functions in insulation, water repellency, display and signalling [11-13] and is known to diversify both through natural and sexual selection [14]. Within tetrapods, preserved soft tissues have informed the evolution of flight structures in birds, bats and pterosaurs [6,15], as well as other integument-enabled locomotor modes [16]. The timing of origin of tetrapod body coverings in the fossil record is crucial for understanding when different integumentary novelties arose [17-21]. However, a recent summary of the fossil record of integumentary structures in Archosauria remarked that, although clades with scales, filaments and pycnofibres [22-24] have Triassic origins [20], a key interval in integumentary evolution based on genomic data [19], their earliest fossil records are in the Jurassic, nearly $100 \mathrm{Myr}$ after the estimated clade origin. Moreover, despite the recent finding that the molecular machinery involved in hair and feather formation was probably present in the amniote ancestor $[19,21]$, there has been very little evidence for what the ancestral amniote integument may have looked like $[21,25,26]$. Here, we ask: (i) how the distribution of land-dwelling vertebrate Lagerstätten varies across time and space; (ii) whether previously proposed explanatory variables for temporal variation in Phanerozoic Konservat-Lagerstätten distribution (e.g. atmospheric $\mathrm{CO}_{2}$, non-marine rock outcrop area, global sea-level change) or subclade biodiversity estimates explain the tetrapod records; (iii) whether there are differences in the preservation potential of different integumentary types; and (iv) if among-integument variation in preservation might bias reconstructed first origins of novel integumentary structures. Elucidating the pattern and potential drivers of tetrapod soft tissue preservation may inform potential systematic biases in our understanding of the evolution of these structures more generally.

\section{Material and methods}

\section{(a) Lagerstätten occurrence database}

We performed a comprehensive literature search to build a database of instances of tetrapod soft tissue preservation through time. There have been various definitions of exceptional preservation $[7,8,27,28]$. The working definition that we employ in this paper is in the sense of soft tissue preservation [2], rather than museum-quality fossils [27]. In accordance with the criteria of a Konservat-Lagerstätte used in this study [2], trackways, footprints and subfossil remains were omitted. To account for localities that sample the same fauna, such as the Jehol Biota in China, all localities in a single Formation were treated as a single occurrence (e.g. the Jiufotang, Yixian and Chaomidian Formations), so that the same age and location was not counted twice in one time bin. Each deposit was classified as lacustrine, fluvial, other terrestrial (amber/opal, coprolite) or estuarine/near-shore marine based on published information (see electronic supplementary material, dataset S1). Deposits classified as 'near-shore marine' include estuarine and lagoonal settings as well as proximal shelf settings that harbour terrestrial organisms. Previous studies did not choose to incorporate amber deposits due to the rarity of such deposits in deep time and uncertainty concerning the validity of older reported cases of amber-preserved integuments [7,8]. However, amber was included here, because it has been recognized as a particularly important source of data on tetrapod integument, a recent review has removed some uncertainty about the validity of preserved amber specimens [29] and it has been possible to discount several previous reported instances of integument preservation [30].

To account for uncertainty in Lagerstätte age, we used an integration approach (see electronic supplementary material).

\section{(b) Data sources}

Sea level was previously proposed as a driver of Lagerstätten through time [7]. We used a composite sea-level dataset from [31] and [32]; a truncated version of the dataset in [31] spanning from 0 to $250 \mathrm{Ma}$; and an additional dataset from [33]. $\delta^{18} \mathrm{O}$ levels are linked to temperature variation during icehouse intervals [34]. We used $\delta^{18} \mathrm{O}$ as a variable in our analyses, because global temperatures and glaciation can affect the formation of lakes and may also be linked to terrestrial tetrapod biodiversity, and we wanted to control these relationships statistically. We used raw data that included $\delta^{18} \mathrm{O}$ from calcite and aragonite shells [35] and interpolated the data for each $10 \mathrm{My}$ time bin using locally weighted scatterplot smoothing $($ span $=0.15)$. We included atmospheric $\mathrm{CO}_{2}$ levels from two sources [36-38] as a predictor variable because $\mathrm{CO}_{2}$ was previously hypothesized to influence the preservation of soft tissues [8]. The number of fossils found may be linked to the amount of available sediments; therefore, we included terrestrial rock outcrop area also as a variable in our analyses [39]. To account for the possibility that Lagerstätten are more frequent when there are more organisms to be preserved, we used a tetrapod dataset [40] with the number of families known from the fossil record living at a given point in time as our proxy for biodiversity. Finally, we included current country and continent land areas as a proxy for collecting bias (Food and Agriculture Organization, http://faostat3.fao.org/home/E). Climate proxy data were handled in two ways: (i) averaged over the entire bin duration or (ii) interpolated using the 'approx' function in $\mathrm{R}$ and then subsampled at the edge of discrete time bins (see electronic supplementary material, figure S1; R code available at Dryad). A $10 \mathrm{My}$ bin size was chosen for our primary analyses given the average age resolution (7 Ma) in our fossil database.

\section{(c) Pairwise correlations among time series}

To test whether some integument types co-occur in Lagerstätten, we computed the phi statistic (correlation between two binary variables) and used $\chi^{2}$ tests to test for significance. To test whether different integument types showed similar trends through time, we used pairwise Spearman rank correlation tests on detrended time series. Time series were detrended using generalized differencing [41] with code written by G. Lloyd (available at http://www. graemetlloyd.com/methgd.html). All pairwise $p$-values were adjusted using Bonferroni correction.

\section{(d) Predicting the number of Lagerstätten through time} We used multiple regression to compare the number of Lagerstätten per time bin against sea level, fossil age, atmospheric 
$\mathrm{CO}_{2}$ level, terrestrial biodiversity, $\delta^{18} \mathrm{O}$ and total terrestrial rock outcrop area for all bin sizes (5-30 My, $5 \mathrm{My}$ increments). We used quasi-Poisson multiple regression with a backward elimination of non-significant $(p<0.05)$ variables to determine the most parsimonious model for explaining variation in the number of Lagerstätten through time. Quasi-Poisson distributions were used, because (i) data transformations to normality are not advisable for count data [42] and (ii) our response variable (integrated number of Lagerstätten in a given time bin) had non-integer values. In cases where model residuals were not normal (assessed using quantile-quantile plots in R) or showed evidence of heteroscedasticity, we applied either fourth-root transformations [43] or used zero-inflated Poisson regression [44] implemented in the PSCL R package. To test the sensitivity of our analyses to time bin width and climate proxy dataset used, we ran analyses for several time bin widths and using distinct $\mathrm{CO}_{2}[36,37]$ and sea-level datasets [31-34]. We further assessed whether significant autocorrelation existed between the residuals using autocorrelation functions (see electronic supplementary material, figure S4). A positive correlation between subsequent residuals could inflate $t$-values and thereby increase Type I error. That our statistical results were similar for a wide range of time bin widths (see electronic supplementary material, figure S7) suggests that autocorrelation does not influence our results.

\section{(e) Gap analysis to estimate earliest occurrences of}

\section{integument types}

We first used a gap analysis approach that estimates confidence intervals (CIs) for when the earliest record might be expected to be found based on the number of fossil horizons (unique Lagerstätten in our case) and overall time range between first and last known occurrences [45]. As this approach requires that fossils are randomly distributed through time, we also used a second, distribution-free approach that models CIs based on gaps between adjacent fossil finds [46]. Finally, we used a Bayesian approach that simultaneously estimates first occurrence dates as well as recovering potential [47]. The latter method accounts statistically for varying fossil recovery potential with age and uncertainty in the gap size distribution, even when the distribution of Lagerstätten through time is indistinguishable from random [47], resulting in longer $90 \%$ CIs. For all three methods, we computed both $50 \%$ and $90 \%$ CIs; point estimates of earliest occurrences discussed in the text are based on the range specified by the lower bound of the 50\% CIs of [46] and [47]. None of these three methods incorporate biodiversity estimates in computing CIs for earliest appearances in the fossil record. However, as we find either a weak or no relationship between number of Lagerstätten and standing biodiversity estimates (see electronic supplementary material, figure S11), this variable seems to be a poor proxy for sampling intensity.

\section{Results}

\section{(a) Depositional environment}

Land vertebrates are most commonly known from fluvial and lacustrine settings [48], and similarly $83 \%$ of described tetrapod Konservat-Lagerstätten were from lacustrine, fluvial or other terrestrial (e.g. amber) palaeoenvironments (figure 1a). Lagerstätten were significantly more common in lacustrine settings $(46.5 \%, 67 / 144)$ and less common in other terrestrial settings (amber, coprolites; $11.8 \%, 17 / 144$ ) than expected by chance $\left(\chi^{2}=40.5\right.$, d.f. $\left.=3, p<0.001\right)$. Near-shore marine and lacustrine settings were previously reported as the most common environments for Konservat-Lagerstätten preserving non- marine organisms [7,53]. Lagerstätten sampling tetrapod integuments were also common in fluvial environments from the Carboniferous to the Palaeocene (figure 1a). Indeed, fluvial deposits were the most common Lagerstätten type during the Late Cretaceous (figure 1a), especially in North America and parts of Asia (figure $1 b$ ). In other regions, lacustrine and near-shore marine deposits dominate the fossil record for the Late Cretaceous (figure 1). Both the earliest skin and hair records are from fluvial environments, while the earliest scales and filaments are from near-shore marine settings and the earliest feathers are from lacustrine settings (see electronic supplementary material, dataset S1).

Different integument types were unevenly distributed in different depositional environments (table 1). This pattern was mainly driven by Lagerstätten preserving scales, which were significantly more likely to be from fluvial settings and less likely to be from lacustrine settings, and feathers, which showed the opposite pattern (table 1). Hairs were more abundant in amber and coprolites $(40.0 \%, 6 / 15)$ than feathers $(16.5 \%, 13 / 79)$, filaments $(9.1 \%, 1 / 11)$, scales $(3.8 \%$, $1 / 26)$ or skin $(0 \%, 0 / 49)$.

\section{(b) Sea level, $\mathrm{CO}_{2}, \delta^{18} 0$ and land area}

The overall number of tetrapod Konservat-Lagerstätten through time was significantly associated with higher global sea levels $(p<0.001$; electronic supplementary material, figure $\mathrm{S} 5 b)$ and higher $\delta^{18} \mathrm{O}$ values $(p<0.001$; electronic supplementary material, figure $\mathrm{S} 5 a$ ). Neither $\mathrm{CO}_{2}$, previously reported as a predictor of Lagerstätte preservation [8], nor tetrapod biodiversity was significantly correlated with Lagerstätten count (both $p>0.05$ ). These results were similar for two different $\mathrm{CO}_{2}$ datasets (see electronic supplementary material, figure S6), as well as three different sea-level datasets and time bin sizes (see electronic supplementary material, figure S7). Like the overall count, the number of Lagerstätten in lacustrine environments was significantly positively correlated with both global sea level and $\delta^{18} \mathrm{O}$ values (figure $2 a$; electronic supplementary material, figure S10 and table S2), while Lagerstätten from fluvial environments significantly tracked only global sea levels (figure $2 a$; electronic supplementary material, figure S10, and table S2). However, we find that lacustrine Lagerstätten are not significantly more common during greenhouse conditions $\left(\chi^{2}=3.51\right.$, d.f. $=1, p=0.061$; figure $1 a)$. Again, these results were generally not affected by the bin size used; all time bins similar to the resolution of our fossil dataset $(5,10 \mathrm{Ma})$ yielded the same recovered relationships (see electronic supplementary material, table S6).

The spatial distribution of Lagerstätten may reflect sampling intensity, as many Lagerstätten are known from geographical regions with greater land area as well as qualitatively greater numbers of palaeontologists or long traditions of palaeontological research (figure $1 b$; e.g. Germany, North America, China). Indeed, the relationship between number of localities bearing Lagerstätten and current country land area was significantly positive, both with including all countries (Poisson regression, $\beta=0.31 \pm 0.03$ s.e., $z=9.62, p<0.001$; electronic supplementary material, figure S2) and also for a subset of countries with counts above 0 (Poisson regression, $\beta=0.29, z=6.15$, d.f. $=31, p<0.001$ ). However, when evaluated by current continental area, the relationship between Lagerstätten count and land area no longer holds (Pearson's $r=0.34, p=0.45$; electronic supplementary material, figure S3), 
(a)

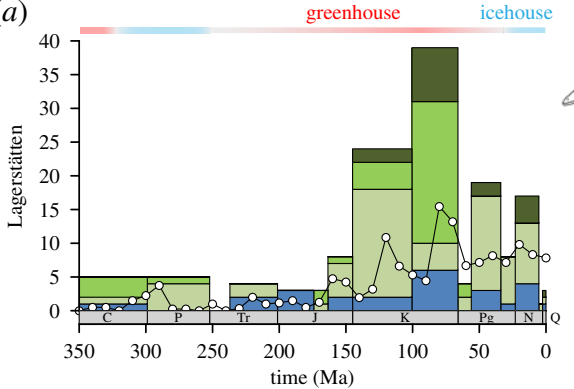

(c)

(c)

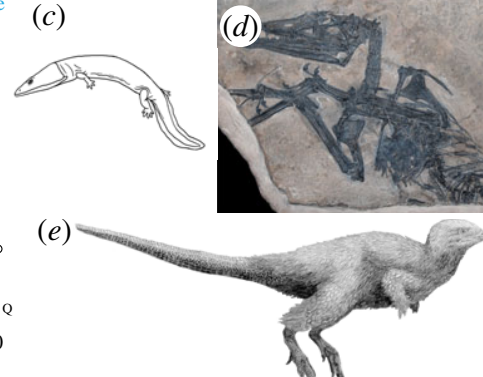

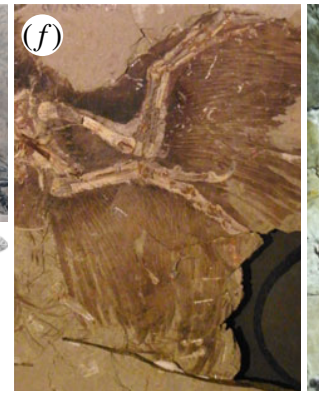

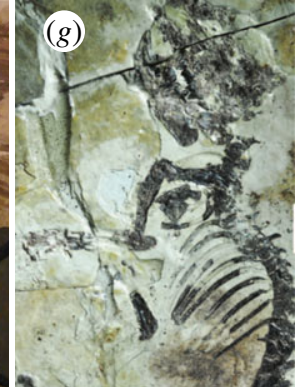

(b)

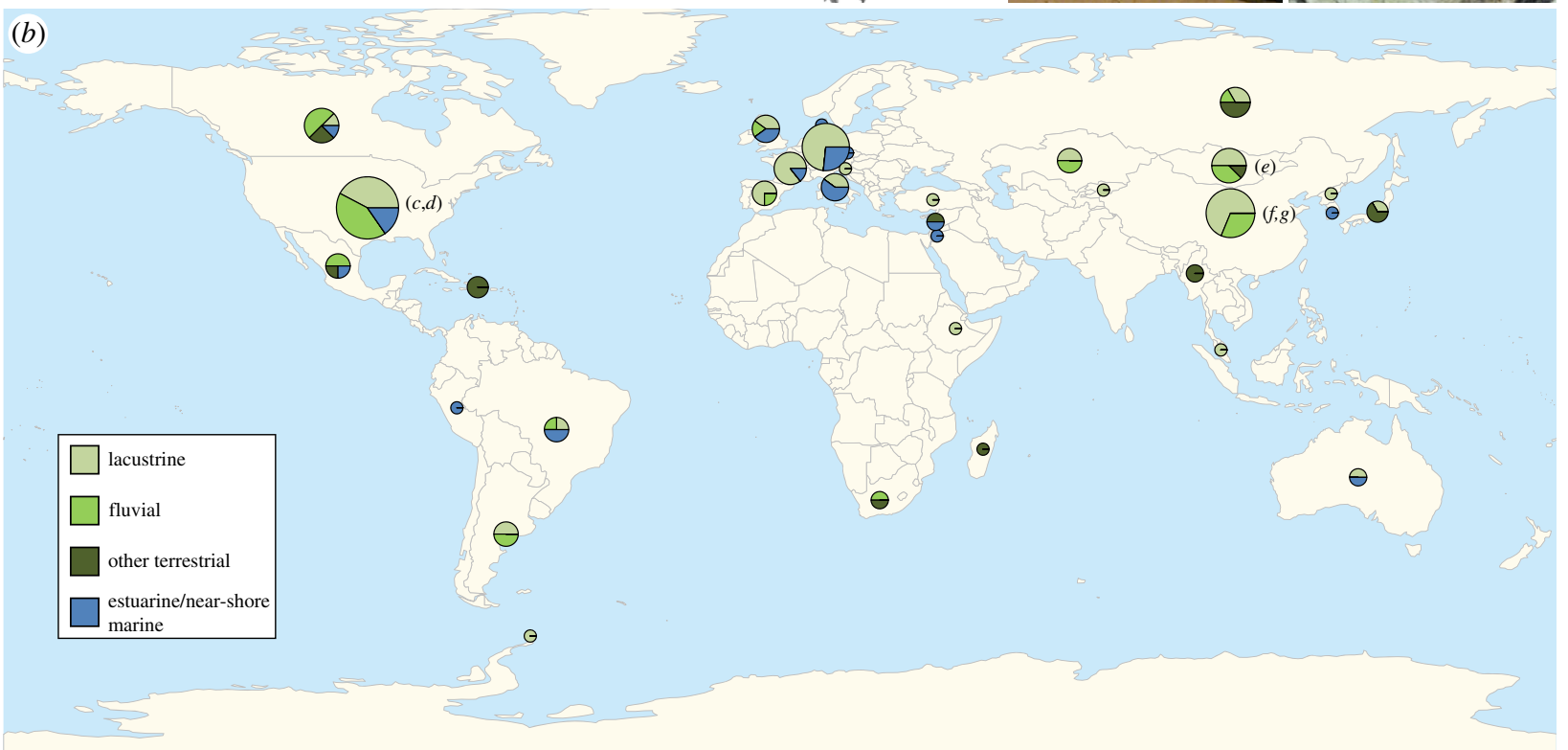

Figure 1. Distribution of tetrapod Konservat-Lagerstätten through time and space $(n=143)$. (a) Numbers of Lagerstätten found in fluvial (light green), lacustrine (medium green), near-shore marine (blue) and other terrestrial depositional environments (dark green) are shown on the $y$-axis by period as well as epoch (for the Mesozoic and (enozoic). For all statistical analyses, we used 10 My time bins after assessing the influence of time bin size on our statistical results (see electronic supplementary material, figure S7). (b) Global distribution of Lagerstätten found in different depositional environments. Pies show relative numbers in different depositional environments (colours of pie) and absolute number per country (size of pie). (c) Earliest skin impressions in Saurerpeton [49]. (d) Earliest putative filaments in Eudimorphodon rosenfeldi [50]. (e) Scales in the ornithischian dinosaur Kulindadromeus zabaikalicus [24]. ( $f$ ) Earliest known feathers in Anchiornis huxleyi [51]. (g) Earliest preserved hair in Rugosodon eurasiaticus [52]. Image credits: (c) Smokeybjb (CC BY-SA 3.0), (d) Tommy from Arad (CC BY 2.0), (e) Tomopteryx (CC BY-SA 4.0), (f) Kumiko (CC BY-SA 2.0), (g) Zhe-Xi Luo (University of Chicago). (Online version in colour.)

suggesting again that these trends may be related to historical or geopolitical variables and not to simply land area.

\section{(c) Integument type, biodiversity trends and gap analyses}

We show statistically different preservation trends among integument types (figure $2 b$ and table 1 ; electronic supplementary material, table S5). The number of tetrapod KonservatLagerstätten preserving skin and feathers was significantly $(p<0.05)$ positively correlated with sea level and negatively correlated with $\delta^{18} \mathrm{O}$, one proxy for global temperature (figure $2 b$; electronic supplementary material, table S4). Among integument types, only feather-bearing Lagerstätten were significantly associated with higher rock outcrop areas (see electronic supplementary material, table S4). During the Miocene, there is an increased amount of observed terrestrial outcrop area (figure $2 b$ ) but fewer known feather-bearing Lagerstätten occurrences than would be predicted by our statistical model (see electronic supplementary material, figure S9). Exceptional scale preservation was significantly linked to periods of high global sea levels (see electronic supplementary material, table S4). Filament-bearing Lagerstätten, only known from the Mesozoic, were significantly more frequent in time periods with high atmospheric $\mathrm{CO}_{2}$ levels (figure $2 b$ ). The number of Lagerstätten containing hairs was significantly positively correlated with synapsid biodiversity (figures $2 b$ and $3 b$; electronic supplementary material, table S4). Some integument types showed significantly similar trends in preservation potential through time (e.g. feathers and hair; Spearman rank correlation tests, $p<0.05$ ), while others did not (e.g. feathers and filaments in the subclade Archosauria, $p>0.05$; figure $2 b$ ). Only skin and scales significantly co-occur in the same Lagerstätten, whereas feathers are significantly more likely to be found in the absence of skin and scales (see electronic supplementary material, table S5).

To estimate the earliest that each integument type may have arisen, we used three gap analysis approaches, modelling the relationship between sampling and probability of first occurrence $[45-47,54]$. These analyses suggest that feathers likely arose close to their oldest known fossil record, $172 \mathrm{Ma}$ (figure 3a). By contrast, filaments (pycnofibres or 'protofeathers') probably arose 257-274 Ma, before their earliest known records in stem archosaurs (figure 3a). Gap analyses based on [47] showed overlapping CIs for skin and scales (figure $3 b$ ). The fossil record of hair is poor, and thus its estimated origin is estimated by all methods to be substantially earlier than its first appearance in the fossil 
(a)
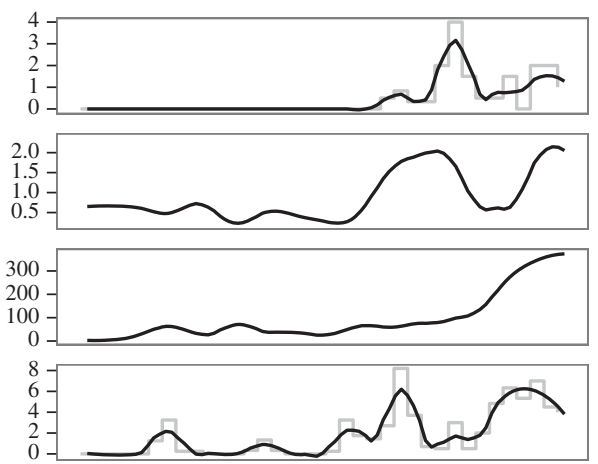

兰
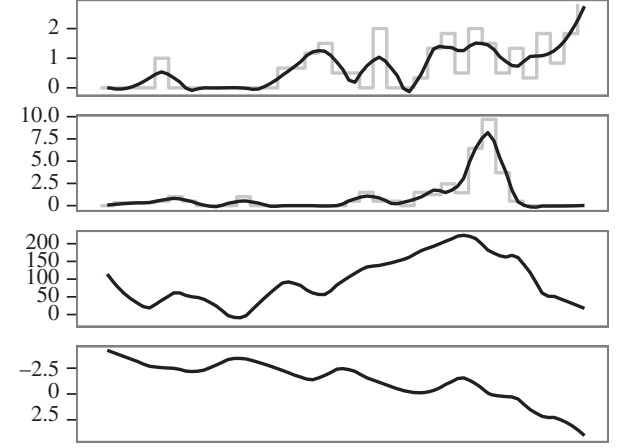

$2500-$

$2000=$
$1500-$
$1000-$

1000
$500-$

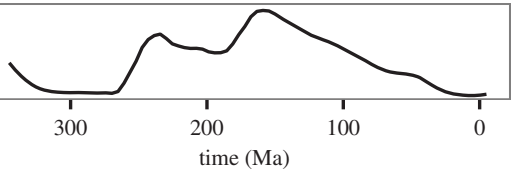

(b)
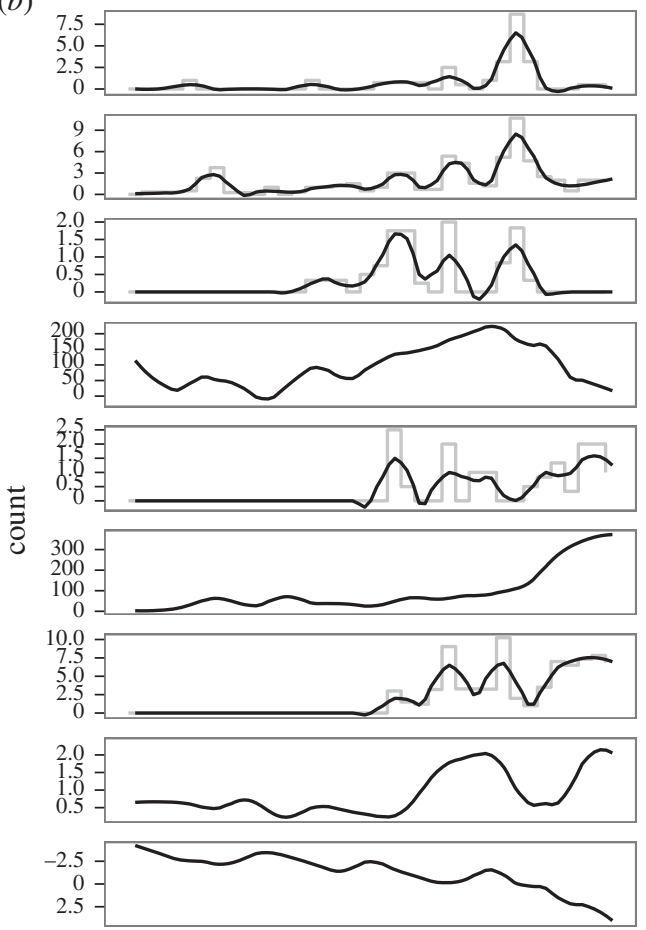

$2500=$
$2000=$
$1500=$
1000
500

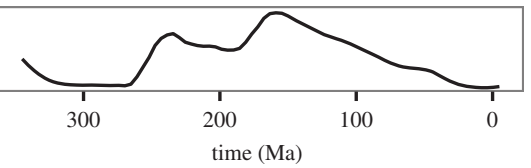

scales

skin

filaments

sea level

\section{䢨}

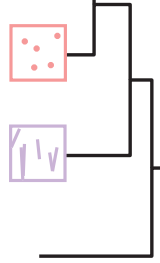

hair

terrestrial

biodiversity

feathers

rock

outcrop area

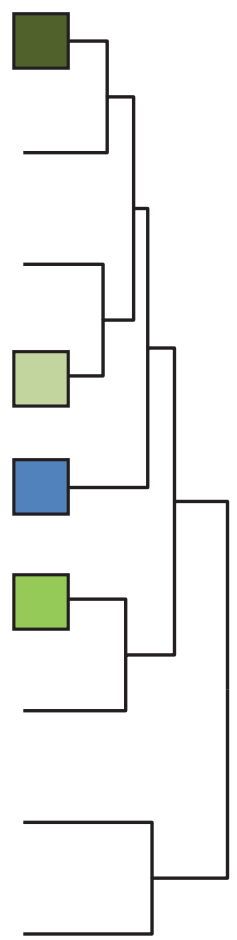

Figure 2. Comparative time-series analysis of Lagerstätten preservation through time. Vertical panels show time series of palaeoenvironmental data and number of Lagerstätten for different $(a)$ depositional environments and $(b)$ integument types. Dendrograms show hierarchical clustering of time-series data with Euclidean distances on the $x$-axis (e.g. two variables directly connected by a short path indicate similar trends with time). Variables were scaled to have a standard deviation of unity prior to computing Euclidean distances and running a clustering analysis. Lagerstätten counts were integrated over $10 \mathrm{My}$ bins (see electronic supplementary material. figure S1). Note that curves for climatic/tectonic variables are smoothed here to make it easier to visualize trends in the data, but unsmoothed per bin values were used in all statistical analyses. Sea level estimates are from composite of [31] and [32], as presented in [34]. Global terrestrial rock outcrop area is from [39]. Atmospheric $\mathrm{CO}_{2}$ data taken are from [36] and are an average of global proxies. See electronic supplementary material, figure $\$ 12$ for units and more detailed information. (Online version in colour.) 

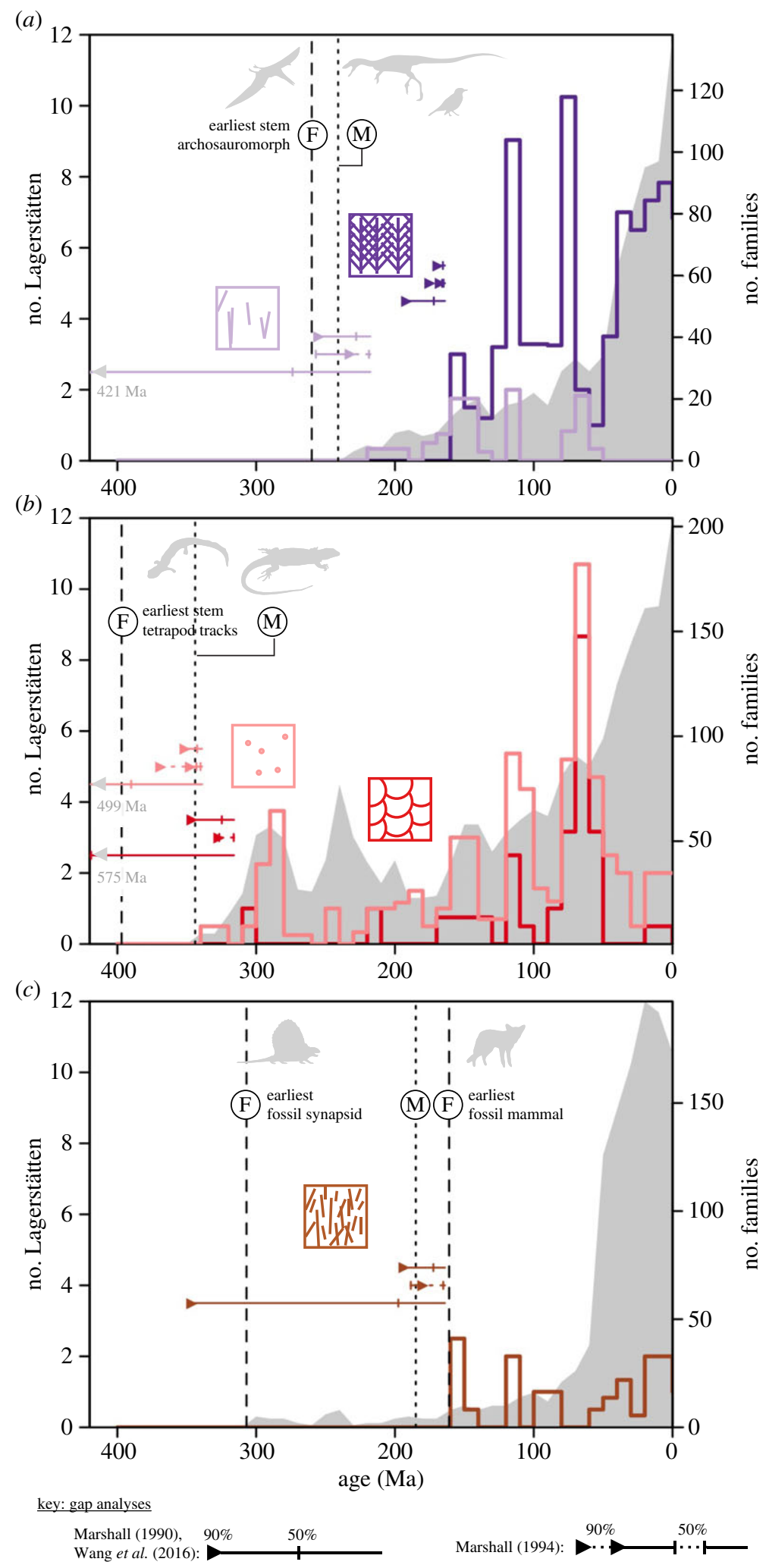

Figure 3. The fossil record of integumentary innovations in tetrapods. Panels correspond to (a) filaments (light purple) and feathers (dark purple), (b) skin (pink) and scales (red) and (c) hair (brown). Grey polygons (secondary y-axis) show a proxy for tetrapod biodiversity (number of families) [40]. Age ranges for the earliest first appearances of an integumentary type based on gap analyses using three different methods [45-47,54] are shown as horizontal bars: (a) method of [45,54]; (b) method of [46]; (c) method of [47]. Arrowheads represent $90 \%$ Cls for estimated earliest occurrence in the fossil record, vertical lines represent 50\% Cls and dashed lines indicate uncertainty in these intervals estimated by Marshall [46] (see key). In some cases, lower bounds on the 90\% Cl estimated by Marshall [46] could not be calculated due to limited fossil data (indicated by missing arrowheads). For visualization purposes, cases where the lower bound of $90 \% \mathrm{Cl}$ extend beyond the $x$-axis range are indicated with grey arrowheads. Gap analyses were performed using the mean age range of individual Lagerstätten (see electronic supplementary material, table S7 for results using minimum and maximum of age ranges). Vertical dashed lines present early body or trace fossils as context for the integumentary records: in (a), archosauromorph Eorasaurus [55], $260 \mathrm{Ma}$; in (b), indet. stem tetrapod tracks, $397 \mathrm{Ma}$ [56], reviewed in [57]; in (c), synapsid Eocasea martini, $315 \mathrm{Ma}$ [58,59] and oldest known crown mammal, Megaconus mammaliaformis, $161 \mathrm{Ma}$ [60]. Vertical dotted lines are molecular divergence estimates for (a) crown archosaurs (241 Ma), (b) tetrapods (344 Ma) [61] and (c) crown mammals (185 Ma) [62]. (Online version in colour.) 
Table 1. Tetrapod integuments are unevenly preserved in different depositional environments. Table shows number of preserved integuments associated with different depositional environments. There was an overall significant relationship between integument type and environment $\left(\chi^{2}=51.9\right.$, d.f. $\left.=12, p<0.001\right)$. Values in parentheses are standardized residuals, with italics representing significantly higher, or lower, counts than expected by chance ( \pm 3 s.d. from the expected value).

\begin{tabular}{|c|c|c|c|c|c|}
\hline depositional environment & feathers & filaments & skin & scales & hair \\
\hline fluvial & $8(-4.6)$ & $2(-0.73)$ & $25(2.14)$ & $18(5.28)$ & $2(-1.3)$ \\
\hline lacustrine & $50(3.61)$ & $5(-0.1)$ & $28(-1.04)$ & $3(-3.75)$ & $7(-0.02)$ \\
\hline estuarine/near-shore marine & $12(-0.21)$ & $3(1.09)$ & $12(0.62)$ & $2(-1.13)$ & $2(-0.26)$ \\
\hline other terrestrial & $10(1.14)$ & $1(-0.06)$ & $2(-2.26)$ & $2(-0.29)$ & $4(2.33)$ \\
\hline
\end{tabular}

record (figure 3c). Hairs are estimated to have arisen around 189-198 Ma, up to $15 \mathrm{My}$ before the origin of crown mammals (approx. $185 \mathrm{Ma}$ ) and $40 \mathrm{My}$ before their oldest occurrence in the fossil record (161 Ma; electronic supplementary material, table S7), but well after (approx. $100 \mathrm{My}$ ) the oldest stem synapsids (figure $3 c$ ).

\section{Discussion}

We show statistically that indeed the distribution of KonservatLagerstätten preserving terrestrial vertebrate integument is uneven, like the Phanerozoic record for these Lagerstätten overall (figure 1). While correlated with sea level and some climate proxies ( $\delta^{18} \mathrm{O}$ values) (figures 1 and 2; electronic supplementary material, figure S5), these global trends do not fully explain the observed patterns. Biodiversity proxies, $\mathrm{CO}_{2}$ and rock outcrop area were not significantly correlated with total Lagerstätten number. However, several of these variables did show a relationship with the distribution of records of particular integument types (figure $2 b$; electronic supplementary material, figure S11). In terms of spatial trends, present-day land area was a significant predictor of how many Lagerstätten localities were found in a given country (see electronic supplementary material, figure S2). However, this trend is not seen when continental land area is used (see electronic supplementary material, figure S3). This result and the distribution of areas with few to zero known Konservat-Lagerstätte suggest that bias in sampling intensity is a key driver of spatial variation in occurrences (figure 1).

Integument records were most common in number of lacustrine Lagerstätten, as previously reported [63], and these records were similarly significantly positively correlated with both global sea level and $\delta{ }^{18} \mathrm{O}$ values (figure $2 a$; electronic supplementary material, figure S10 and table S2). Greenhouse conditions have been linked to periods of increased volcanic input [64]. In lacustrine settings, high ash concentrations might have be expected to influence fossil preservation affecting chemical permeability during diagenesis [65] or, more directly, through pyroclastic flow-driven burial and transport of organisms into lakes [66]. However, again, no relation was recovered with $\mathrm{CO}_{2}$ or these identified greenhouse intervals (figure 1; electronic supplementary material, figure S6). This result is somewhat surprising given the observed statistical relationship with global sea level and $\delta^{18} \mathrm{O}$ values. Global climate proxies $\left(\delta^{18} \mathrm{O}\right.$, atmospheric $\left.\mathrm{CO}_{2}\right)$ are related, especially during some (e.g. icehouse) intervals, but precise high-resolution reconstructions of atmospheric $\mathrm{CO}_{2}$ levels in deep time are an ongoing challenge (e.g. $[35,37,67,68]$ ). It may be that a relationship between the total number of Konservat-Lagerstätten through time and other climate proxies will be recovered with further consensus on these values, increased resolution in the Mesozoic, or better age resolution for fossil occurrence data, which may simply be too coarse on a time scale (approx. 7 My average uncertainty) to recover relationships with more rapid temporal fluctuations in atmospheric $\mathrm{CO}_{2}$ [37].

Further investigation of recovered patterns requires further fine-scale analyses of variation in Lagerstätten over narrower geographical regions and shorter time intervals [69]. Regional tectonic and climatic controls may be as important as global trends, especially when collecting bias is taken into account. Temporal variation in distinct palaeoenvironments suitable for preserving different integumentary types or events in earth history (e.g. origin of resin-producing plants) may also affect this distribution [53]. We find that the frequency of exceptional preservation in different depositional environments varies by time period (figure $1 a$ ), a pattern that remains incompletely explained $[7,9]$. For example, Konservat-Lagerstätten in the Early Cretaceous are primarily in lacustrine environments, but there are comparatively few occurrences in these environments in the Late Cretaceous (figure 1a; electronic supplementary material, figures S8 and S10); the opposite is true for fluvial deposits. This pattern also holds at finer geographical scales. All Early Cretaceous Lagerstätten from China are lacustrine (4/4 100\%), whereas most Late Cretaceous formations from Asia are fluvial (2/4,50\% in China, 2/2 in Mongolia). Similarly, the only Early Cretaceous Lagerstätten in North America are from a lacustrine setting, while $7 / 9$ (78\%) of Late Cretaceous occurrences are found in fluvial settings. Recovered links with both sea-level datasets used for fluvial and total Lagerstätten occurrences merit further investigation. This link makes sense if high sea levels affect the land area covered by fluvial sediments $[69,70]$, as sea-level-driven fluvial aggradation has been demonstrated both observationally [69] and experimentally [71]. An important area for future research not investigated here will be facies-specific analyses. Variation in energy, depositional environment and taphonomic factors within fluvial, lacustrine and near-shore marine settings is significant and not investigated here. Many reported Lagerstätten simply lack this level of reported detail.

We show variation in preservation among integumentary types. Some integument types show significantly similar preservation patterns through time (e.g. filaments, skin and scales; figure $2 b$; electronic supplementary material, table S5) consistent with potential links to similar abiotic factors (e.g. global sea-level variation or conditions associated with fluvial environments (table 1) or explained by co-occurrence of distinct integumentary types in the same organism (e.g. skin and scales in dinosaurs; electronic supplementary material, table S5). However, feathers and filaments, both common to Archosauria 
but not often found in the same organism [6], show very different trends through time (figure $2 b$ ) and rarely have been recovered in the same Lagerstätte (see electronic supplementary material, table S5). Overall, our results show that some 'bursts' of soft tissue preservation (figure 3) are so far better explained by favourable depositional settings and changes in abiotic factors rather than variation in subclade biodiversity (see electronic supplementary material, table S4 and figure S11).

We asked how variation in apparent preservation potential might affect our inferences of integumentary origins. The fossil record of mammalian hairs and archosaurian filaments is extremely limited especially when compared with that of feathers and skin (table 1). The earliest estimated occurrence of feathers based on gap analysis is very close to the estimated origin of maniraptoran dinosaurs (167-172 Ma; 50\% CI), suggesting that biases in soft tissue preservation do not significantly influence estimates of the origin of pinnate feathers (figure $3 a$ ). Filaments are known from pterosaurs, ornithischian dinosaurs and theropod dinosaurs $[6,20]$. Whether these represent three distinct origins of filaments or a single gain in archosaurs has remained unclear [20]. However, that the $90 \% \mathrm{CI}$ on the time of origin of feathers does not extend beyond the known stratigraphic range of filaments (figure $3 a$ ) supports an origin for feathers post-dating that of filaments and lends support to the 'single gain' hypothesis rather than multiple origins in different archosaur groups.

The paucity of Lagerstätten preserving hairs (15/143, 10\%) is surprising given the proposed high potential for hair preservation [72] and significant mammalian biodiversity in the Cenozoic (figure $3 c$ ). Differences in the preservation potential of $\alpha$-keratin due to the differences in its chemical structure relative to that of feather keratin [26] and/or the ability to identify isolated hairs may explain this pattern. Recent fossil evidence has suggested that hairs may pre-date the phylogenetic divergence between monotremes and other crown mammals (eutherians and metatherians) [60]. Here, gap analyses reveal that the lower bound of the $50 \%$ CI for the estimated first appearance of hairs in the fossil record is $198 \mathrm{Ma}$, pre-dating the estimated origin of crown mammals [62] and much earlier than previously recognized, in stem mammaliaforms (figure $3 c$ ). This estimate is also consistent with molecular and physiological considerations, as the genetic machinery for making hairs was in place well before the diversification of synapsids, with high numbers of $\alpha$-keratin genes present in early tetrapods $[19,73]$, and small sizes and nocturnality [74] in Jurassic stem mammals could have acted as agents of selection on insulating function in early proto-hairs [11].

Recent molecular and developmental evidence suggests that skin was the ancestral body covering in tetrapods [75], consistent with the skin outlines in stem taxa with osseous structures lying entirely within the dermis; 'dermal scales' [76]. Our results are not in conflict with this finding. The best estimate for the origin of skin is $343-390 \mathrm{Ma}$, while that for scales is 327$419 \mathrm{Ma}$, both near the estimated origin of crown tetrapods (figure $3 b$ ). However, preservation of these integument types in the fossil record is too poor to say with confidence whether the earliest skin records pre-date those of keratinous scales. Indeed, the lower bound of the $90 \%$ CI extends to well before the earliest known evidence of tetrapods in the fossil record. Further work is obviously needed to understand the body coverings of early tetrapods. The fossil record is not rich enough to permit strong inferences about which came first, skin or scales.

Our results indicate that variation in preservation potential among integuments can lead to biases in the reconstructed first origins of novel integumentary structures. Thus, we asked what factors might explain these patterns of uneven preservation potential of integuments through time. Given variation in the chemistry of their components [26], variation in resistance to decomposition in distinct integumentary structures may be expected [72,77]. Among integument types, only the limited record of hair preservation in 15 total Lagerstätten was significantly predicted by biodiversity (figure $2 b$; electronic supplementary material, figure S11). For the much richer records of other integumentary types, environmental and/or taphonomic factors are more important (figure $2 b$ ). The relative paucity of feathers from fluvial environments (table 1) might be explained by the high-energy fluvial processes that would destroy smaller, more delicate integumentary structures [78]. By contrast, skin and scales are often preserved either as casts or three-dimensional impressions [72], and many of their records are associated with large-bodied organisms (see electronic supplementary material, dataset S1) and distinct embedding processes. These differences might explain the significantly higher number of records of skin and scales in fluvial deposits (table 1).

Data accessibility. The primary fossil dataset used in statistical analyses is available as electronic supplementary material. Additional datasets used in statistical analyses have been uploaded to Dryad as http:// dx.doi.org/10.5061/dryad.1c5k9 [79].

Authors' contributions. C.M.E., J.A.C., L.H., H.G. and T.W. compiled the dataset. J.A.C. designed the study. C.M.E. and L.H. performed statistical analyses. C.M.E. and J.A.C. wrote the manuscript.

Competing interests. We declare we have no competing interests.

Funding. Funding for this work was provided by the National Science Foundation (grant no. EAR 1251922 to J.A.C).

Acknowledgements. Ke-qin Gao, Lauren English, Zhiheng Li and James Proffitt are gratefully acknowledged for assistance with early data collection and discussion. We thank Andrew Knoll, Brian Horton, Lorenzo Alibardi, Zhe-Xi Luo, R. Wayne Wager, Florian Witzmann, James Schiffbauer, Charles Marshall and one anonymous reviewer for insightful discussion and thoughtful comments that greatly improved this manuscript.

\section{References}

1. Briggs DEG. 2003 The role of decay and mineralization in the preservation of soft-bodied fossils. Annu. Rev. Earth Planet. Sci. 31, 275301. (doi:10.1146/annurev.earth.31.100901. 144746)

2. Seilacher A. 1970 Begriff und bedeutung der FossilLagerstätten. Neues Jarhbuch Geol. Palaöntol. Monatshefte 1970, 34-39.
3. Bottjer DJ, Etter W, Hagadorn JW, Tang CM. 2005 Fossillagerstätten: jewels of the fossil record. In Exceptional fossil preservation: a unique view on the evolution of marine life (eds DJ Bottjer, W Etter, JW Hagadorn, CM Tang), pp. 1-10. New York, NY: Columbia University Press.

4. Martin T, Marugán-Lobón J, Vullo R, Martín-Abad H, Luo Z-X, Buscalioni AD. 2015 A Cretaceous 
6. Xu X, Zhou Z, Dudley R, Mackem S, Chuong CM, Erickson GM, Varricchio DJ. 2014 An integrative approach to understanding bird origins. Science 346, 1253293. (doi:10.1126/science.1253293)

7. Allison PA, Briggs DEG. 1993 Exceptional fossil record: distribution of soft-tissue preservation through the Phanerozoic. Geology 21, 527-530. (doi:10.1130/ 0091-7613(1993)021<0527:EFRDOS>2.3.(0;2)

8. Retallack GJ. 2011 Exceptional fossil preservation during $\mathrm{CO}_{2}$ greenhouse crises? Palaeogeogr. Palaeodlimatol. Palaeoecol. 307, 59-74. (doi:10. 1016/j.palaeo.2011.04.023)

9. Schiffbauer JD, Laflamme M. 2012 Lagerstätten through time: a collection of exceptional preservational pathways from the terminal neoproterozoic through today. Palaios 27, 275-278. (doi:10.2110/palo.2012.503)

10. Allison PA. 1988 Konservat-Lagerstätten: cause and classification. Paleobiology 14, 331-344. (doi:10. 1017/S0094837300012082)

11. Ling JK. 1970 Pelage and molting in wild mammals with special reference to aquatic forms. Q. Rev. Biol. 45, 16-54. (doi:10.1086/406361)

12. Stettenheim PR. 2000 The integumentary morphology of modern birds - an overview. Am. Zool. 40, 461-477. (doi:10.1093/icb/40.4.461)

13. Gorb $S$ (ed). 2009 Functional surfaces in biology: little structures with big effects. Berlin, Germany: Springer Science \& Business Media.

14. West-Eberhard MJ. 1983 Sexual selection, social competition, and speciation. Q. Rev. Biol. 58, 155 - 183. (doi:10.1086/413215)

15. Simmons NB, Geisler JH. 1998 Phylogenetic relationships of Icaronycteris, Archaeonycteris, Hassianycteris, and Palaeochiropteryx, with comments on the evolution of the echolocation and foraging strategies in Microchiroptera. Bull. Am. Mus. Nat. Hist. 235, 1-182.

16. Daza JD, Stanley EL, Wagner P, Bauer AM, Grimaldi DA. 2016 Mid-Cretaceous amber fossils illuminate the past diversity of tropical lizards. Sci. Adv. 2, e1501080. (doi:10.1126/sciadv.1501080)

17. Prum RO. 1999 Development and evolutionary origin of feathers. J. Exp. Zool. 285, 291-306. (doi:10.1002/(SICI)1097-010X(19991215)285: 4<291::AID-JEZ1>3.0.(0;2-9)

18. Xu X, Zhou Z, Prum RO. 2001 Branched integumental structures in Sinornithosaurus and the origin of feathers. Nature 410, 200-204. (doi:10. 1038/35065589)

19. Lowe $C B$, Kellis $M$, Siepel A, Raney BJ, Clamp M, Salama SR, Kingsley DM, Lindblad-Toh K, Haussler D. 2011 Three periods of regulatory innovation during vertebrate evolution. Science 333, 1019-1024. (doi:10.1126/science.1202702)

20. Clarke J. 2013 Feathers before flight. Science 340, 690-692. (doi:10.1126/science.1235463)

21. Lowe CB, Clarke JA, Baker AJ, Haussler D, Edwards SV. 2015 Feather development genes and associated regulatory innovation predate the origin of Dinosauria. Mol. Biol. Evol. 32, 23-28. (doi:10. 1093/molbev/msu309)
22. Kellner AW, Wang $X$, Tischlinger $H$, de Almeida Campos D, Hone DW, Meng X. 2010 The soft tissue of Jeholopterus (Pterosauria, Anurognathidae, Batrachognathinae) and the structure of the pterosaur wing membrane. Proc. R. Soc. B 277, 321-329. (doi:10.1098/rspb.2009.0846)

23. Rauhut OW M, Foth C, Tischlinger H, Norell MA. 2012 Exceptionally preserved juvenile megalosauroid theropod dinosaur with filamentous integument from the Late Jurassic of Germany. Proc. Natl Acad. Sci. USA 109, 11746-11 751. (doi:10. 1073/pnas.1203238109)

24. Godefroit P, Sinitsa SM, Dhouailly D, Bolotsky YL, Sizov AV, McNamara ME, Benton MJ, Spagna P. 2014 A Jurassic ornithischian dinosaur from Siberia with both feathers and scales. Science $\mathbf{3 4 5}$, 451-455. (doi:10.1126/science.1253351)

25. Alibardi L, Valle LD, Nardi A, Toni M. 2009 Evolution of hard proteins in the sauropsid integument in relation to the cornification of skin derivatives in amniotes. J. Anat. 214, 560-586. (doi:10.1111/j. 1469-7580.2009.01045.x)

26. Alibardi L. 2012 Perspectives on hair evolution based on some comparative studies on vertebrate cornification. J. Exp. Zool. 318, 325-343. (doi:10. 1002/jez.b.22447)

27. Schuchert C. 1915 Revision of paleozoic stelleroidea: with special reference to North American asteroidea. Bull. Nat. Mus. 88, 1-311.

28. Seilacher A, Reif W-E, Westphal F, Riding R, Clarkson E, Whittington HB. 1985 Sedimentological, ecological and temporal patterns of fossil Lagerstätten [and Discussion]. Phil. Trans. R. Soc. Lond. B 311, 5-24. (doi:10.1098/rstb.1985.0134)

29. Poinar G0. 1992 Life in amber. Stanford, CA: Stanford University Press.

30. Grimaldi DA, Shedrinsky A, Ross A, Baer NS. 1994 Forgeries of fossils in 'amber': history, identification and case studies. Curator Mus. J. 37, 251-274. (doi:10.1111/j.2151-6952.1994.tb01023.x)

31. Haq BU, Hardenbol J, Vail PR. 1987 Chronology of fluctuating sea levels since the triassic. Science 235, 1156-1167. (doi:10.1126/science.235.4793. 1156)

32. Haq BU, Al-Qahtani AM. 2005 Phanerozoic cycles of sea-level change on the Arabian Platform. GeoArabia 10, 127-160.

33. Vail PR, Mitchum Jr RM, Thompson III S. 1977 Seismic stratigraphy and global changes of sea level: part 4. Global cycles of relative changes of sea level. Am. Assoc. Pet. Geologists Mem. 26, 83-97.

34. Miller KG et al. 2005 The Phanerozoic record of global sea-level change. Science 310, 1293-1298. (doi:10.1126/science.1116412)

35. Veizer J, Godderis Y, François LM. 2000 Evidence for decoupling of atmospheric $\mathrm{CO}_{2}$ and global climate during the Phanerozoic eon. Nature 408, 698-701. (doi:10.1038/35047044)

36. Royer DL, Berner RA, Park J. 2007 Climate sensitivity constrained by $\mathrm{CO}_{2}$ concentrations over the past 420 million years. Nature 446, 530-532. (doi:10. 1038/nature05699)
37. Retallack GJ. 2009 Greenhouse crises of the past 300 million years. Geol. Soc. Am. Bull. 121, 1441-1455. (doi:10.1130/B26341.1)

38. Berner RA. 2006 GEOCARBSULF: a combined model for Phanerozoic atmospheric $\mathrm{O}_{2}$ and $\mathrm{CO}_{2}$. Geochim. Cosmochim. Acta 70, 5653-5664. (doi:10.1016/j. gca.2005.11.032)

39. Wall PD, Ivany LC, Wilkinson BH. 2011 Impact of outcrop area on estimates of Phanerozoic terrestrial biodiversity trends. Geol. Soc. Lond. 358, 53-62. (doi:10.1144/SP358.5)

40. Benton MJ. 1996 Testing the roles of competition and expansion in tetrapod evolution. Proc. R. Soc. Lond. B 263, 641-646. (doi:10.1098/rspb.1996.0096)

41. McKinney ML. 1990 Classifying and analysing evolutionary trends. In Evolutionary trends (ed. JC McNamara), pp. 28-58. London, UK: Belhaven Press.

42. O'Hara RB, Kotze DJ. 2010 Do not log-transform count data. Methods Ecol. Evol. 1, 118-122. (doi:10.1111/j.2041-210X.2010.00021.x)

43. Zar JH. 1999 Biostatistical analysis (4th edition). Upper Saddle River, NJ: Prentice-Hall.

44. Zeileis A, Kleiber C, Jackman S. 2008 Regression models for count data in R. J. Stat. Softw. 27, 1-25. (doi:10.18637/jss.v027.i08)

45. Marshall CR. 1990 Confidence intervals on stratigraphic ranges. Paleobiology 16, 1-10. (doi:10.1017/S0094837300009672)

46. Marshall CR. 1994 Confidence intervals on stratigraphic ranges: partial relaxation of the assumption of randomly distributed fossil horizons. Paleobiology 20, 459-469. (doi:10.1017/ S0094837300012938)

47. Wang SC, Everson PJ, Zhou HJ, Park D, Chudzicki DJ. 2016 Adaptive credible intervals on stratigraphic ranges when recovery potential is unknown. Paleobiology 42, 240-256. (doi:10.1017/pab.2015.37)

48. Behrensmeyer AK et al. 1992 Paleoenvironmental contexts and taphonomic modes. In Terrestrial ecosystems through time (eds AK Behrensmeyer, JD Damuth, WA DiMichele, R Potts, H-D Sues, SL Wing), pp. 15-136. Chicago, IL: University of Chicago Press.

49. Milner AR. 1982 Small temnospondyl amphibians from the Middle Pennsylvanian of Illinois. Palaeontology 25, 635-664.

50. Dalla Vecchia FM. 2009 Anatomy and systematics of the pterosaur Carniadactylus gen. n. rosenfeldi (Dalla Vecchia, 1995). Rivis. Ital. Paleontol. Strati.115, 159-188.

51. Li Q, Clarke JA, Gao K-Q, Zhou C-F, Meng Q, Li D, D’Alba L, Shawkey MD. 2014 Melanosome evolution indicates a key physiological shift within feathered dinosaurs. Nature 507, 350-353. (doi:10.1038/nature12973)

52. Yuan CX, Ji Q, Meng QJ, Tabrum AR, Luo ZX. 2013 Earliest evolution of multituberculate mammals revealed by a new Jurassic fossil. Science $\mathbf{3 4 1}$, 779-783. (doi:10.1126/science.1235905)

53. Briggs DEG. 2003 Lagerstätten. In Palaeobiology II (eds DEG Briggs, PR crowther), pp. 328-332. Oxford, UK: Blackwell Publishing. 
54. Strauss D, Sadler PM. 1989 Classical confidence intervals and Bayesian probability estimates for ends of local taxon ranges. Math. Geol. 21, 411-427. (doi:10.1007/BF00897326)

55. Ezcurra MD, Scheyer TM, Butler RJ. 2014 The origin and early evolution of Sauria: reassessing the Permian saurian fossil record and the timing of the crocodile-lizard divergence. PLOS ONE 9, e89165. (doi:10.1371/journal.pone.0089165)

56. Niedźwiedzki G, Szrek P, Narkiewicz K, Narkiewicz M, Ahlberg PE. 2010 Tetrapod trackways from the early Middle Devonian period of Poland. Nature 463, 43-48. (doi:10.1038/nature08623)

57. George D, Blieck A. 2011 Rise of the earliest tetrapods: an early Devonian origin from marine environment. PLoS ONE 6, e22136. (doi:10.1371/ journal.pone.0022136)

58. Brocklehurst N, Kammerer CF, Fröbisch J. 2013 The early evolution of synapsids, and the influence of sampling on their fossil record. Paleobiology 39, 470-490. (doi:10.1666/12049)

59. Reisz RR, Fröbisch J. 2014 The Oldest Caseid Synapsid from the Late Pennsylvanian of Kansas, and the evolution of herbivory in terrestrial vertebrates. PLOS ONE 9, e94518. (doi:10.1371/ journal.pone.0094518.5006)

60. Zhou C-F, Wu S, Martin T, Luo Z-X. 2013 A Jurassic mammaliaform and the earliest mammalian evolutionary adaptations. Nature 500, 163-167. (doi:10.1038/nature12429)

61. Shen X-X, Liang D, Wen J-Z, Zhang P. 2011 Multiple genome alignments facilitate development of NPCL markers: a case study of tetrapod phylogeny focusing on the position of turtles. Mol. Biol. Evol. 28, 3237-3252. (doi:10.1093/molbev/msr148)

62. Reis dos M, Inoue J, Hasegawa M, Asher RJ, Donoghue PCJ, Yang Z. 2012 Phylogenomic datasets provide both precision and accuracy in estimating the timescale of placental mammal phylogeny. Proc. R. Soc. B 279, 3491-3500. (doi:10.1073/pnas. 122231299)

63. Davis P, Briggs D. 1995 Fossilization of feathers. Geology 23, 783. (doi:10.1130/0091-7613(1995) $023<0783: \mathrm{FOF}>2.3 .(0 ; 2)$

64. McKenzie NR, Horton BK, Loomis SE, Stockli DF, Planavsky NJ, Lee C-TA. 2016 Continental arc volcanism as the principal driver of icehousegreenhouse variability. Science 352, 444-447. (doi:10.1126/science.aad5787)

65. Briggs D, Crowther PR (eds). 2008 Palaeobiology II, pp. 1-130. New York, NY: John Wiley \& Sons.

66. Jiang B, Harlow GE, Wohletz K, Zhou Z, Meng J. 2014 New evidence suggests pyroclastic flows are responsible for the remarkable preservation of the Jehol biota. Nat. Commun. 5, 3151. (doi:10.1038/ ncomms4151)

67. Breecker DO, Sharp ZD, McFadden LD. 2010 Atmospheric $\mathrm{CO}_{2}$ concentrations during ancient greenhouse climates were similar to those predicted for AD 2100. Proc. Natl Acad. Sci. USA 107, 576-580. (doi:10.1073/pnas.0902323106)

68. Foster GL, Rohling EJ. 2013 Relationship between sea level and climate forcing by $\mathrm{CO}_{2}$ on geological timescales. Proc. Natl Acad. Sci. USA 110, 1209-1214. (doi:10.1073/pnas.1216073110)

69. Blum MD, Törnqvist TE. 2000 Fluvial responses to climate and sea-level change: a review and look forward. Sedimentology 47, 2-48. (doi:10.1046/j. 1365-3091.2000.00008.x)

70. Porebski SJ, Steel RJ. 2006 Deltas and sea-level change. J. Sedimentary Res. 76, 390-403. (doi:10. 2110/jsr.2006.034)

71. Van Heijst M, Postma G. 2001 Fluvial response to sea-level changes: a quantitative analogue, experimental approach. Basin Res. 13, 269-292. (doi:10.1046/j.1365-2117.2001.00149.x)

72. Schweitzer MH. 2011 Soft tissue preservation in terrestrial mesozoic vertebrates. Annu. Rev. Earth Planet. Sci. 39, 187-216. (doi:10.1146/annurevearth-040610-133502)

73. Vandebergh W, Bossuyt F. 2012 Radiation and functional diversification of alpha keratins during early vertebrate evolution. Mol. Biol. Evol. 29, 995-1004. (doi:10.1093/molbev/msr269)

74. Angielczyk KD, Schmitz L. 2014 Nocturnality in synapsids predates the origin of mammals by over 100 million years. Proc. R. Soc. $B$ 281, 20141642. (doi:10.1093/bioinformatics/ btr315)

75. Di-Poi N, Milinkovitch MC. 2016 The anatomical placode in reptile scale morphogenesis indicates shared ancestry among skin appendages in amniotes. Sci. Adv. 2, e1600708. (doi:10.1126/ sciadv.1600708)

76. Witzmann F. 2007 The evolution of the scalation pattern in temnospondyl amphibians. Zool. J. Linn. Soc. 150, 815-834. (doi:10.1111/j.1096-3642.2007. 00309.x)

77. Briggs DEG, Summons RE. 2014 Ancient biomolecules: their origins, fossilization, and role in revealing the history of life. Bioessays 36, 482-490. (doi:10.1002/bies.201400010)

78. Behrensmeyer AK. 1988 Vertebrate preservation in fluvial channels. Palaeogeogr. Palaeoclimatol. Palaeoecol. 63, 183-199. (doi:10.1016/00310182(88)90096-X)

79. Eliason CM, Hudson L, Watts T, Garza H, Clarke JA. 2017 Data from: Exceptional preservation and the fossil record of tetrapod integument. Dryad Digital Repository. (http://dx.doi.org/10.5061/ dryad.1c5k9) 